\title{
Significant decrease of von Willebrand factor and plasminogen activator inhibitor-1 by providing supplementation with selenium and coenzyme Q10 to an elderly population with a low selenium status
}

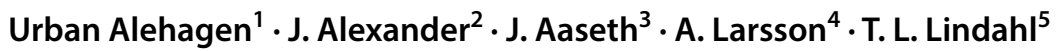

Received: 17 June 2019 / Accepted: 28 January 2020 / Published online: 20 February 2020

(c) The Author(s) 2020

\begin{abstract}
Purpose Endothelial dysfunction and inflammation are conditions which fuel atherosclerosis and ischaemic heart disease. We have previously reported reduced cardiovascular (CV) mortality following supplementation with selenium and coenzyme Q10 to 443 elderly individuals with low selenium status (mean $67 \mu \mathrm{g} / \mathrm{L}$ ) for 4 years. Here, we wanted to evaluate a possible association between the supplementation and the plasma concentrations of the von Willebrand factor (vWf), and the plasminogen activator inhibitor-1 (PAI-1), as they, besides other functions, are also strongly associated with endothelial function. Methods In this sub-study, 308 individuals (active substance: 157, placebo: 151) were included. Blood samples were drawn after 6 and 36 months and vWf and PAI-1 were determined in plasma by ELISA. Changes in concentrations of the biomarkers were evaluated by the use of $T$ tests, repeated measures of variance, and ANCOVA analyses.

Results The active treatment group presented a lower level of vWf after 36 months compared with the placebo group (1.08 $\mathrm{U} / \mathrm{mL}$ vs. $5.10 \mathrm{U} / \mathrm{mL} ; p=0.0007)$. The results were validated through the repeated measures of variance evaluation. The PAI-1 levels showed an equally significant decrease in the active group $(26.2 \mathrm{ng} / \mathrm{mL}$ vs. $49.2 \mathrm{ng} / \mathrm{mL} ; p=0.0002)$ and were also validated through repeated measures of variance evaluation.

Conclusion In this sub-study on elderly receiving selenium and coenzyme Q10, or placebo we found significantly lower levels of vWf and PAI-1 in the active treatment group as compared to the placebo group. We interpret this as a better endothelial function because of the intervention, which accords with a previous finding of reduced CV mortality.
\end{abstract}

Keywords Von willebrand factor · PAI-1 - Intervention · Elderly $\cdot$ Selenium $\cdot$ Coenzyme Q10

$\begin{array}{ll}\text { Abbreviations } \\ \text { ACEI } & \text { ACE- inhibitors } \\ \text { ANCOVA } & \text { Analysis of covariance } \\ \text { ANOVA } & \text { Analysis of variance } \\ \text { ARB } & \text { Angiotension receptor blockers } \\ \text { EF } & \text { Ejection fraction } \\ \text { ECG } & \text { Electrocardiogram } \\ \text { Hs-CRP } & \begin{array}{l}\text { High sensitivity analysis of C-reactive } \\ \text { protein }\end{array} \\ \text { IHD } & \text { Ischemic heart disease } \\ \text { NYHA class } & \begin{array}{l}\text { New York Heart Association functional } \\ \text { class }\end{array} \\ \text { PAI-1 } & \text { Plasminogen activator inhibitor-1 }\end{array}$

Urban Alehagen

Urban.Alehagen@liu.se

Extended author information available on the last page of the article

\section{SD}

vWf

\section{Introduction}

Selenium is one of the trace elements found as selenoproteins in the living cells that are essential for a normal cellular function [1,2]. The most important selenoproteins are selenoprotein $\mathrm{P}$, glutathione peroxidases, and thioredoxin reductase, all of which protect against oxidative stress.

In Europe, a low selenium content of the soil results in low dietary selenium intake [3-7], and biofortification has therefore been proposed $[8,9]$. In contrast, in the United States the selenium content in the soil is generally higher $[10,11]$. 
Ubiquinone (coenzyme Q10) is a powerful antioxidant that is also needed for optimal function of all living cells [12]. An intricate interrelationship between selenium and coenzyme Q10 has been reported Xia et al., indicating that both groups are needed in order to obtain normal cellular function, and are related to each other [13]. The endogenous production of coenzyme Q10 decreases with increasing age, where the endogenous production of coenzyme Q10 in the myocardium is about half at the age of 80 compared to 20 years [14].

A trial where elderly community-living persons received a combined supplementation of selenium and coenzyme Q10 for 4 years has been published [15]. The choice of giving both selenium and coenzyme Q10 as supplementation was based on the facts that a low selenium intake had been shown in the same population, a decreased endogenous production of coenzyme Q10 was known due to the high age, and that there is an interrelationship between the two substances within the cell. One of the main results from the study was a significant reduction in cardiovascular (CV) mortality [15].

The von Willebrand factor (vWf) is a plasma glycoprotein with an important function in primary haemostasis and in coagulation as it is the major carrier for factor VIII. vWF is produced and stored in endothelial cells and platelets. It mediates the adhesion process of platelets to endothelial surfaces [16], where the vWf is anchored to the endothelium through fibres [17]. The factor has a multitude of functions, including controlling angiogenesis [18], and also acting as an acute phase reactant as the Weibel-Palade bodies release the inflammation mediators [19]. However, there have been observations indicating that an increased concentration of $\mathrm{vWf}$ is also a sign of vascular dysfunction [19]. Several reports have demonstrated the association between increased concentration of $\mathrm{vWf}$ and $\mathrm{CV}$ disease or myocardial infarction [20-22].

Plasminogen activator inhibitor-1 (PAI-1) has wellknown antifibrinolytic effects, and is secreted from endothelial cells and hepatocytes [23, 24] and also synthesised and stored in platelets [25]. It is a serpin and exerts its antifibrinolytic effect by forming a 1:1 complex with tissue plasminogen activator upon cleavage of its "bait" peptide bond $\operatorname{Arg}_{346}-\mathrm{Met}_{347}$ [26]. Interesting data indicate that PAI-1 is also involved in the development of diabetes type II, and in insulin resistance $[27,28]$. Also, several reports have pointed to an association between PAI-1 and ischaemia and coronary artery pathology as a higher level of PAI-1 has been observed in patients with ischaemic heart disease or myocardial infarction [29, 30]. Endothelial dysfunction of the coronary arteries could also be found in those without diabetes, but with signs of insulin resistance [31].

Aim We have previously reported the effect of supplementation with selenium and coenzyme Q10 on the level of inflammation as seen on biomarkers for inflammation. In this sub-study we wanted to evaluate a possible effect of the intervention on endothelial function and inflammation, applying the concentration of the biomarkers $\mathrm{vWf}$ and PAI1 , as markers of endothelial function.

\section{Methods}

\section{Subjects}

This is a sub-study of a prospective randomised double-blind placebo-controlled trial where 443 elderly community-living subjects in the age range $70-88$ years were subjected to dietary supplementation of selenium and coenzyme Q10 for 4 years. From the main study, significantly reduced CV mortality, increased cardiac systolic function, and a reduced concentration of the cardiac peptide NT-proBNP could be reported as results of the intervention [15]. The subjects were given dietary supplementation of $200 \mathrm{mg} /$ day of coenzyme Q10 capsules (Bio-Quinon $100 \mathrm{mg}$ B.I.D, Pharma Nord, Vejle, Denmark) and $200 \mu \mathrm{g} /$ day of organic selenium yeast tablets (SelenoPrecise $200 \mu \mathrm{g}$, Pharma Nord, Vejle, Denmark) $(n=221)$, or a similar placebo $(n=222)$ over 48 months, after which the intervention was finished. The study supplementation was taken in addition to regular medication if used. All study medications (active drug and placebo) not consumed were returned and counted. All participants were examined by one of three experienced cardiologists. A clinical history was recorded at inclusion, and a clinical examination was performed, including blood pressure, assessment of New York Heart Association functional class (NYHA class) as well as ECG and echocardiography. Doppler echocardiographical examinations were performed with the participant in the left lateral position. The ejection fraction (EF) readings were categorised into four classes with interclass limits placed at 30\%, $40 \%$ and $50 \%[32,33]$. Normal systolic function was defined as $\mathrm{EF} \geq 50 \%$, while severely impaired systolic function was defined as $\mathrm{EF}<30 \%$. The inclusion started in January 2003 and finished in February 2010.

CV mortality was registered for all study participants. The mortality information was obtained from the National Board of Health and Welfare in Sweden, which registers all deaths of Swedish citizens based on death certificates or autopsy reports. Written, informed consent was obtained from all patients.

\section{Ethical approval}

The study was approved by the Regional Ethical Committee (Forskningsetikkommmitten, Hälsouniversitetet, SE-581 85 Linköping, Sweden; No. D03-176), and conforms to the 
ethical guidelines of the 1975 Declaration of Helsinki. (The Medical Product Agency declined to review the study protocol since the study was not considered a trial of a medication for a certain disease but rather one of food supplement commodities that are commercially available). This study was registered at Clinicaltrials.gov and has the identifier NCT01443780. Since it was not mandatory to register at the time the study began, the study has been registered retrospectively.

\section{Biochemical analyses}

Blood samples were collected after 6 and 36 months while the participants were resting in a supine position. Prechilled, EDTA vials containing plasma were used. The vials were centrifuged at $3000 \mathrm{~g},+4{ }^{\circ} \mathrm{C}$, and were then frozen at $-70{ }^{\circ} \mathrm{C}$. No sample was thawed more than once.

\section{Determination of the von Willebrand factor and PAI-1}

Von Willebrand factor concentration was measured by ELISA with the Technozyme ${ }^{\circledR}$ vWF:Ag kit and PAI-1 with the Technozyme ${ }^{\circledR}$ PAI1:Ag kit. Both kits were purchased from Technoclone, Vienna, Austria. The inter assay variation was $6.0 \%$ and $5.5 \%$, respectively according to the manufacturer.

\section{Statistical methods}

Descriptive data are presented as percentages or mean \pm SD. A Student's unpaired two-sided $T$ test was used for continuous variables and the chi-square test was used for the analysis of one discrete variable. Repeated measures of variance were used to obtain better information on the individual changes in the concentration of the biomarker analysed, compared to group mean values.

As the analysis of variance (ANOVA) algorithm can handle a slight non-Gaussian distribution, non-transformed data were applied in the repeated measures of variance evaluation. In the analysis of covariance (ANCOVA) evaluation, both transformed and non-transformed data were applied, with no significant difference in the results.

In the ANCOVA evaluation, the biomarker concentration after 42 months was used as an independent variable. In the model, adjustments were made for age, hs-CRP, biomarker concentration after 6 months, smoking, hypertension, ischaemic heart disease (IHD), diabetes, and supplementation with selenium and coenzyme Q10, and in the PAI-1 evaluation, also for Body Mass Index.

$p$ values $<0.05$ were considered significant, based on a two-sided evaluation. All data were analysed using standard software (Statistica v. 13.2, Dell Inc, Tulsa, OK, USA).

\section{Results}

In this sub-study, the study population consisted of 308 individuals, of which 157 received active treatment, and 151 received placebo. The figures are based on the number of participants still alive after 36 months, and within the study and who agreed to deliver blood samples after 6 months and after 36 months.

From Table 1 it can be seen that the baseline characteristics are balanced between the two groups at inclusion and thus no significant difference could be seen between the groups (Table 1).

In the study population, 61 out of $308(19.8 \%)$ had diabetes, 223 out of 308 (72.4\%) had hypertension, and 63 out of $308(20.5 \%)$ had IHD thus they were representative of an elderly population in the community.

Table 1 Baseline characteristics of the study population receiving intervention of a dietary supplementation of selenium and coenzyme Q10 combined during 4 years

\begin{tabular}{|c|c|c|c|}
\hline & Active & Placebo & $p$ value \\
\hline$N$ & 157 & 151 & \\
\hline Age years mean (SD) & $76(3)$ & $77(3)$ & 0.34 \\
\hline Males/females $n$ & $79 / 78$ & $72 / 79$ & \\
\hline \multicolumn{4}{|l|}{ History } \\
\hline Diabetes $n(\%)$ & $32(20.4)$ & $29(19.2)$ & 0.80 \\
\hline Smoking $n(\%)$ & $11(7.0)$ & $13(8.6)$ & 0.60 \\
\hline Hypertension $n(\%)$ & $114(72.6)$ & $109(72.2)$ & 0.93 \\
\hline IHD $n(\%)$ & $28(17.8)$ & $35(23.2)$ & 0.25 \\
\hline NYHA class I $n(\%)$ & $93(59.2)$ & $76(50.3)$ & 0.12 \\
\hline NYHA class II $n(\%)$ & $39(24.8)$ & $47(31.1)$ & 0.22 \\
\hline NYHA class III $n(\%)$ & $24(15.3)$ & $26(17.9)$ & 0.65 \\
\hline NYHA class IV $n(\%)$ & 0 & 0 & \\
\hline BMI mean (SD) & $27.4(4.07)$ & $27.0(4.18)$ & 0.44 \\
\hline $\mathrm{Hb}<120 \mathrm{~g} / \mathrm{L} n(\%)$ & $15(9.6)$ & $16(10.6)$ & 0.76 \\
\hline \multicolumn{4}{|l|}{ Medications } \\
\hline ACEI/ARB $n(\%)$ & $30(19.1)$ & $40(26.5)$ & 0.12 \\
\hline Beta blockers $n(\%)$ & $56(35.7)$ & $53(35.1)$ & 0.92 \\
\hline Diuretics $n(\%)$ & $49(31.2)$ & $61(40.4)$ & 0.09 \\
\hline Statins $n(\%)$ & $35(22.3)$ & $32(21.2)$ & 0.81 \\
\hline \multicolumn{4}{|l|}{ Examinations } \\
\hline $\mathrm{EF}<40 \% n(\%)$ & $12(7.6)$ & $11(7.3)$ & 0.90 \\
\hline Atrial fibrillation $n(\%)$ & $9(5.7)$ & $12(7.9)$ & 0.44 \\
\hline $\mathrm{s}$-Selenium $\mu \mathrm{g} / \mathrm{L}$, mean $(\mathrm{SD})$ & $66.6(15.9)$ & $67.4(17.2)$ & 0.56 \\
\hline
\end{tabular}

$A C E I$ ACE-inhibitors, $A R B$ angiotension receptor blockers, $E F$ ejection fraction, $I H D$ ischemic heart disease, NYHA New York Heart Association functional class, $S D$ standard deviation 


\section{Relation between the levels of the von Willebrand factor and PAI-1, and cardiovascular mortality}

In order to determine whether the levels of the $\mathrm{vWf}$ and PAI-1 differed in those participants of the placebo group who had suffered CV mortality within 5,10 , and 12 years of follow-up, the levels of vWf and PAI-1 in the blood samples drawn after 6 months from the two groups were compared. After 5 years, 10 participants had suffered CV mortality, while 113 had not, after 10 years 42 participants had suffered CV mortality, while 81 had not, and finally after 12 years 49 participants had suffered CV mortality and 74 had not in this sub-population. Only those who received the placebo intervention, thus no active supplementation of selenium and coenzyme Q10 were included in this analysis.

After 5 years, numerically higher concentrations of vWf could be seen in the CV mortality group, although these concentrations were not significant, probably due to the small sample size (vWf: $\mathrm{CV}+: 23.7 \mathrm{U} / \mathrm{mL}$ vs $\mathrm{CV}-: 12.0 \mathrm{U} / \mathrm{mL}$; $p=0.20$ ). After 10 years the numerical difference persisted, and a borderline significance was obtained regarding the difference between the two groups $(\mathrm{CV}+: 19.6 \mathrm{U} / \mathrm{mL}$ vs $\mathrm{CV}-$ : 9.4; $p=0.05$ ). After 12 years an even greater difference was obtained, which was now statistically significant $(\mathrm{CV}+: 22.4$ $\mathrm{U} / \mathrm{mL}$ vs $\mathrm{CV}-:$ : $6.8 \mathrm{U} / \mathrm{mL} ; p=0.002$ ).

Performing the same evaluation regarding PAI- 1 , the same message could be found. After 5 years of follow-up, a higher numerical value for concentration could be found, although not significant, probably due to the small sample size (CV+: $43.3 \mathrm{ng} / \mathrm{mL}$ vs CV-: $11.7 \mathrm{ng} / \mathrm{mL} ; p=0.20$. After 10 years of follow-up a significant difference in concentration could be found $(\mathrm{CV}+: 50.4 \mathrm{ng} / \mathrm{mL}$ vs $22.0 \mathrm{ng} / \mathrm{mL}$; $p=0.048$ ), and with a follow-up period of 12 years, in those with a CV mortality a numerically higher level of PAI-1 could be seen $(48.4 \mathrm{U} / \mathrm{mL}$ compared to $28.3 \mathrm{U} / \mathrm{mL} ; p=0.2)$ compared to those who did not suffer CV mortality.

Obviously, an association between the level of the biomarker and CV mortality could be seen. Therefore, the evaluation of supplementation of selenium and coenzyme Q10 and consideration of its possible association with the levels of biomarkers are of interest.

\section{Influence of selenium and coenzyme Q10 on the concentration of the von Willebrand factor}

At the start of the evaluation, after 6 months, no difference in the level of $\mathrm{vWf}$ could be seen (active group: mean $4.6 \mathrm{U} / \mathrm{mL}$ vs placebo: $4.5 \mathrm{U} / \mathrm{mL} ; p=0.99)$. However, after 36 months a significantly higher level of $\mathrm{vWf}$ could be seen in the placebo group compared with the active treatment group $(5.1 \mathrm{U} / \mathrm{mL}$ vs $1.1 \mathrm{U} / \mathrm{mL} ; p=0.0007)$.

Analysing the placebo group during the evaluation period, no difference in level could be demonstrated (6 months: mean $4.5 \mathrm{U} / \mathrm{mL}$ vs. 36 months: $5.1 \mathrm{U} / \mathrm{mL} ; p=0.78$ ). However, in the active treatment group a significant decrease in the level of $\mathrm{vWf}$ could be seen $(4.6 \mathrm{U} / \mathrm{mL}$ vs $1.1 \mathrm{U} / \mathrm{mL}$; $p=0.03$ ).

Applying the repeated measure of variance methodology in order to trace changes between the two time-points with a focus on individual changes, significant differences could also be demonstrated $[F(1,174)=5.20 ; p=0.02]$ (Fig. 1).

To adjust for other variates that could possibly influence the levels of vWf, an ANCOVA evaluation was performed (Table 2). From this evaluation, a significant decrease in $\mathrm{vWf}$ concentration could be seen in the group receiving supplementation with selenium and coenzyme Q10 $(p=0.006)$.

\section{Influence of selenium and coenzyme Q10 on the concentration of PAI-1}

At the start of the evaluation, no difference in the concentration of PAI-1 between the active treatment group and the placebo group could be found $(45.6 \mathrm{ng} / \mathrm{mL}$ vs $48.5 \mathrm{ng} / \mathrm{mL}$; $p=0.79$ ). However, after 36 months a significantly lower concentration of PAI- 1 could be seen in the active treatment group compared with the placebo group (mean $26.2 \mathrm{ng} / \mathrm{mL}$ vs. $49.2 \mathrm{ng} / \mathrm{mL} ; p=0.0002$ ).

In the placebo group, no significant difference in concentration during the evaluation period could be demonstrated (mean $48.5 \mathrm{ng} / \mathrm{mL}$ vs. $49.2 \mathrm{ng} / \mathrm{mL} ; p=0.95$ ), whereas in the active treatment group, a significantly lower concentration was found $(45.6 \mathrm{ng} / \mathrm{mL}$ vs. $26.2 \mathrm{ng} / \mathrm{mL} ; p=0.01)$.

Applying repeated measure of variance regarding the change in concentration in PAI-1, a significant difference between the active treatment group and the placebo group could be demonstrated $[F(1,176)=4.4 ; p=0.037]$ (Fig. 2). Performing an ANCOVA evaluation, a significantly lower concentration ( $p=0.0005)$ could be seen in those supplemented with selenium and coenzyme Q10, also after adjusting for variates that might influence the concentration of PAI-1 (Table 3).

\section{Discussion}

In this sub-study of the KiSel-10 study, where supplementation with selenium and coenzyme Q10 or placebo were provided to elderly community-living participants during 4 years, endothelial function and inflammation were evaluated as reflected by the levels of vWf and PAI-1. We have previously reported that the population was selenium deficient with a mean pre-intervention selenium serum concentration was $67.1 \mu \mathrm{g} / \mathrm{L}$ (SD 16.8) (equivalent to a daily intake of $35 \mu \mathrm{g}$ ) compared to an adequate status of $\geq 100 \mu \mathrm{g} / \mathrm{L}$ [34] and $210 \mu \mathrm{g} / \mathrm{L}$ (SD59.4) post-intervention [35]. After the 
Fig. 1 Concentration of the von Willebrand factor after 6 and 36 months in the selenium and coenzyme Q10 treatment group compared to the placebo group in the study population. Evaluation performed by the use of repeated measures of variance methodology. Current effect: $F(1,174)=5.19$; $p=0.024$. Vertical bars denote 0.95 confidence intervals. Blue curve: placebo; red curve: active treatment group. Bars indicate $\pm 95 \%$ CI

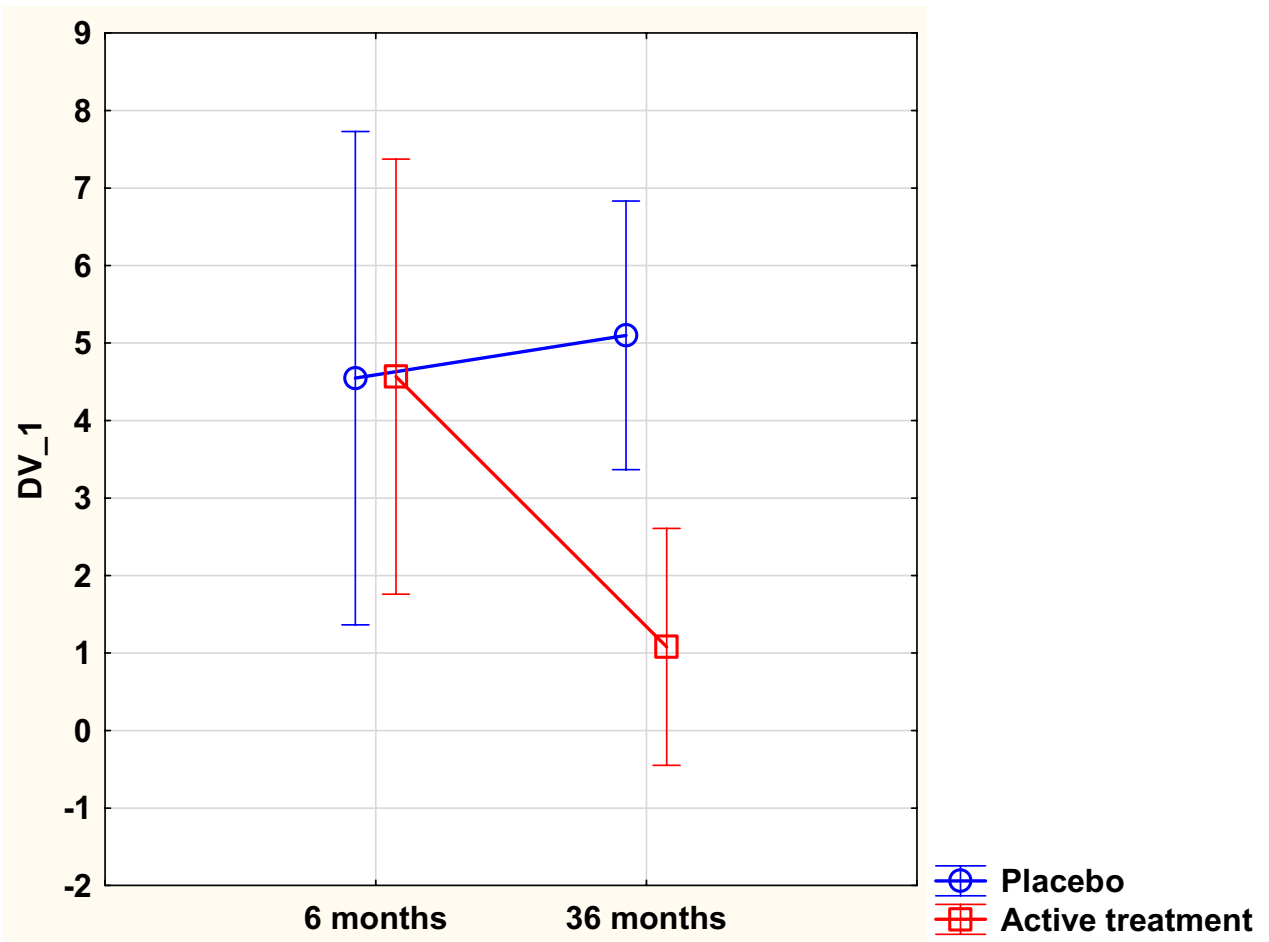

Table 2 Analysis of covariance using von Willebrand factor after 36 months as dependent variable

\begin{tabular}{lccc}
\hline Effects & Sum of squares & $F$ & $p$ \\
\hline Intercept & 14.2 & 0.23 & 0.64 \\
Age & 13.4 & 0.21 & 0.64 \\
HsCRP & 9.9 & 0.16 & 0.69 \\
vWf 6 months & 3829.2 & 61.3 & $<0.0001$ \\
Smoker & 8.3 & 0.13 & 0.72 \\
Hypertension & 3.5 & 0.06 & 0.81 \\
Diabetes & 4.4 & 0.07 & 0.79 \\
IHD & 24.1 & 0.39 & 0.54 \\
Active treatment & 501.6 & 8.03 & 0.006 \\
Error & 4621.6 & & \\
\hline
\end{tabular}

$H s C R P$ high sensitivity assay of CRP, IHD ischemic heart disease, $v W f$ von Willebrand factor

intervention no participant exceeded a selenium concentration of $230 \mu \mathrm{g} / \mathrm{L}$.

An important aspect to discuss is if this supplementation dose is associated with increased risk. It is well known that high intakes of selenium may cause toxicity, i.a. in the liver. Therefore, EU Scientific Committee on Food/ European Food Safety Authority established an upper tolerable intake level (UL) for selenium of $300 \mu \mathrm{g} / \mathrm{day}$ (EFSA 2006) [36]. The Intake level of Se in our study, consisting of a supplementation level of $200 \mu \mathrm{g} / \mathrm{day}$ on top of a dietary intake of much less than $100 \mu \mathrm{g} / \mathrm{day}$ (in the studied population an estimated daily selenium intake of $35 \mu \mathrm{g} / \mathrm{day}$ was demonstrated), was altogether far less than the EFSA UL of $300 \mu \mathrm{g}$. Also, the plasma concentration obtained following supplementation, i.e. $\leq 230 \mu \mathrm{g} / \mathrm{L}$, was below those previously reported associated with adversity [34].

More recently, Rayman et al. reported results from an intervention study in Denmark consisting of 491 individuals [37]. Supplementation levels of 100 and $200 \mu \mathrm{g}$ /day on top of dietary intake provided no evidence of increased risk of mortality; there were, however, wide confidence intervals. The authors claim that an increased mortality risk could be seen in the group supplemented with $300 \mu \mathrm{g} /$ day. However, from the publication the relevant graphs indicate a confidence interval passing the neutrality line after 5 and 10 years and reaches the neutrality line at 15 years of follow-up. The point estimate showing increased mortality should, therefore, be interpreted with great caution according to standard statistical routines. Anyway, this study supports the notion that supplementation up to a level of $200 \mu \mathrm{g} /$ day in a population with low selenium status is safe.

From the literature, we know that the endogenous production of coenzyme Q10 declines to about half at the age of 80 years old, as compared to the level produced at the age of 20 [14]. As the Q10 and the selenoenzyme thioredoxin reductase work in concert reducing Q10 to ubiquinol an important lipidsoluble antioxidant in the cell, this project supplemented both substances.

We observed that the concentration of both $\mathrm{vWf}$ and PAI-1 were significantly lower after 36 months of 
Fig. 2 Concentration of the plasminogen activator inhibitor- 1 after 6 and 36 months in the selenium and coenzyme Q10 treatment group compared to the placebo group in the study population. Evaluation performed by the use of repeated measures of variance methodology. Current effect: $F(1,176)=4.38 ; p=0.038$. Vertical bars denote 0.95 confidence intervals. Blue curve: placebo; red curve: active treatment group. Bars indicate $\pm 95 \%$ CI

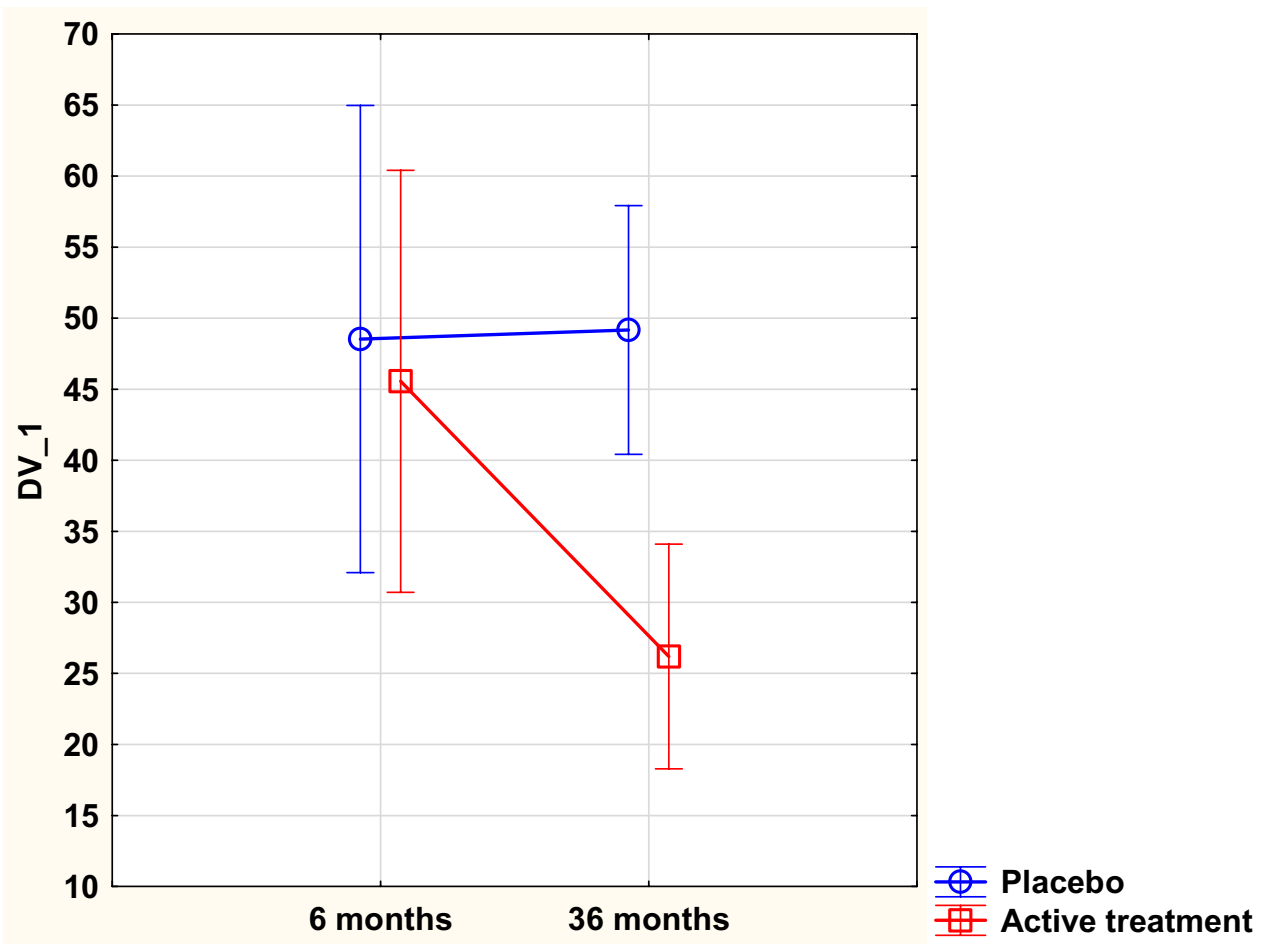

Table 3 Analysis of covariance using PAI-1 after 36 months as dependent variable

\begin{tabular}{lccc}
\hline Effects & Sum of squares & $F$ & $p$ \\
\hline Intercept & 37.8 & 0.07 & 0.80 \\
Age & 48.8 & 0.09 & 0.77 \\
HsCRP & 308.4 & 0.55 & 0.46 \\
PAI-1, 6 months & $23,806.4$ & 42.6 & $<0.0001$ \\
BMI & 1597.4 & 2.9 & 0.09 \\
Smoker & 412.1 & 0.74 & 0.39 \\
Hypertension & 126.3 & 0.23 & 0.64 \\
Diabetes & 160.8 & 0.29 & 0.53 \\
IHD & 48.6 & 0.09 & 0.77 \\
Active treatment & 7857.8 & 14.1 & 0.0003 \\
Error & $41,326.8$ & & \\
\hline
\end{tabular}

$B M I$ Body Mass Index, $H s C R P$ high sensitivity assay of CRP, IHD ischemic heart disease

intervention in the group receiving selenium and coenzyme Q10, compared with those on placebo. This could be seen both in the group mean evaluations and by use of the repeated measures of variance methodology which focuses on individual changes.

As many other clinical variables could influence the level of the biomarkers, ANCOVA evaluations were also performed, in which adjustments for the covariates were made, but still with significant differences between the two groups in levels of the biomarkers.
We have previously observed indications of decreased inflammatory activity accompanying supplementation with selenium and coenzyme Q10, as registered by using six different biomarkers for inflammation [38, 39]. Our present findings regarding the concentrations of $\mathrm{vWf}$ and PAI- 1 are therefore interesting as inflammation and endothelial dysfunction are closely interrelated [40].

However, as the level of vWf is also associated with other conditions such as age and blood type [41], it is important to determine the reason for the increased level by use of another biomarker for inflammation/ endothelial functionin this study, the PAI-1.

In previous studies, vWf was associated with inflammation [42] and a biomarker for vascular damage, which is why it is now also regarded as a marker for endothelial dysfunction [43].

For the second biomarker used in this study, PAI-1, reports in the literature indicate that the level of PAI-1 is associated with inflammation [44]. PAI-1 is also closely associated with endothelial dysfunction, as shown in different conditions [45], including in CV ischaemic disease and myocardial infarction [29].

That supplementation of selenium and coenzyme Q10 could influence the levels of both vWf and PAI-1, as has been shown in this study, is not surprising, even if to the best of our knowledge this is the first time that this has been demonstrated in a patient population through dietary supplementation of selenium and coenzyme Q10. Our group has recently besides effects on inflammation $[38,39]$, reported 
reduced oxidative stress following intervention with selenium and coenzyme Q10 [46], and also changes in expression of mRNA [47] central to inflammation and endothelial function. Therefore, it is not surprising that the intervention also had effect on endothelial function.

Two of the most important selenoproteins, thioredoxin reductase and glutathione peroxidase, have important roles in endothelial cell physiology [48, 49]. As a result, these enzymes regulate both the inflammatory and atherogenic processes. Thus, Stupin et al. in a rat model, observed that selenium deficiency may result in impaired vascular function and increased oxidative stress [50]. The same message could be obtained from human endothelial cells where, in sepsis, a low selenium level results in increased oxidative stress and inflammation [51]. These results concur with the finding in the present study that in those with a selenium deficiency, a positive effect could be obtained by supplementation with selenium and coenzyme Q10 combined.

The participants suffering from CV mortality after 12 years of follow-up of the placebo group exhibited a higher level of the two biomarkers at 6 months, indicating that the biomarker level represents a risk variable for $\mathrm{CV}$ mortality, which is interpreted as the end stage of endothelial dysfunction with inflammation. As the sample size in the present sub-study was small, the differences between the level of the biomarkers in those who suffered CV mortality after 5 and 10 years of follow-up, and the level in those without mortality did not reach statistical significance, even if the actual figures showed a similar difference.

However, the present study demonstrates that supplementation with selenium and coenzyme Q10 to elderly persons with deficiency of the substances affects the endothelial function in a positive way, which adds to the knowledge on the mechanisms behind the positive clinical effects reported earlier.

\section{Limitations}

The presented study has included participants in a relatively narrow age stratum. It is therefore difficult to extrapolate the results into other age groups. However, one could assume that the mechanisms described above also exist in other age strata.

Also, the included study sample is relatively small, which is why the confidence intervals obtained are wide. However, in spite of the reduced size, significant results could be presented in most of the evaluations.

Finally, all included participants were Caucasians that also had a relatively low selenium status; thus, the results do not necessarily apply to other populations, e.g. a selenium replete population.

\section{Conclusion}

The vWf, and PAI-1 act as biomarkers for endothelial function, and inflammation, besides having other different functions. In this sub-study from a 4-year intervention trial of selenium and coenzyme Q10 with elderly community-living persons with a low selenium status, the concentration of the two biomarkers was evaluated and compared between the active treatment group, and the placebo group.

Significantly lower levels of both biomarkers could be demonstrated in the supplemented group after 36 months of intervention. As we have previously reported, signs of less inflammation and an optimized endothelial function might be another of the mechanisms explaining the clinical results from the main study where reduced CV mortality could be reported.

As this is a small study, more research in the field is needed in order to better understand the positive effects of supplementation on individuals with a deficiency of selenium and coenzyme Q10.

Acknowledgements Open access funding provided by Linköping University. Biotechnologist Kerstin Gustafsson and engineer Maria Wallstedt are gratefully acknowledged for performing the analysis of vWf and PAI-1.

Author contributions UA, AL, conceived and designed the research project. UA, and AL conducted the research. TL provided the essential reagents, and the analyses were performed in his lab. UA and AL analysed data and performed the statistical analyses. UA, JAa, JA, TL and AL wrote the paper. UA had the final responsibility for the final content. All authors have read and approved the final manuscript.

Funding Part of the analysis costs was supported by grants from Pharma Nord Aps, Denmark, the County Council of Östergötland, Linköping University. The funding organizations had no role in the design, management, analysis, or interpretation of the data, nor in the preparation, review or approval of the manuscript. No economic compensation was distributed.

\section{Compliance with ethical standards}

Conflict of interest The authors declare no conflicts of interest.

Open Access This article is licensed under a Creative Commons Attribution 4.0 International License, which permits use, sharing, adaptation, distribution and reproduction in any medium or format, as long as you give appropriate credit to the original author(s) and the source, provide a link to the Creative Commons licence, and indicate if changes were made. The images or other third party material in this article are included in the article's Creative Commons licence, unless indicated otherwise in a credit line to the material. If material is not included in the article's Creative Commons licence and your intended use is not permitted by statutory regulation or exceeds the permitted use, you will need to obtain permission directly from the copyright holder. To view a copy of this licence, visit http://creativecommons.org/licenses/by/4.0/. 


\section{References}

1. Fairweather-Tait SJ, Bao Y, Broadley MR, Collings R, Ford D, Hesketh JE, Hurst R (2011) Selenium in human health and disease. Antioxid Redox Signal 14:1337-1383. https://doi. org/10.1089/ars.2010.3275

2. Selenius M, Rundlof AK, Olm E, Fernandes AP, Bjornstedt M (2010) Selenium and the selenoprotein thioredoxin reductase in the prevention, treatment and diagnostics of cancer. Antioxid Redox Signal 12:867-880. https://doi.org/10.1089/ars.2009.2884

3. Van Cauwenbergh R, Robberecht H, Van Vlaslaer V, Deelstra $\mathrm{H}$ (2004) Comparison of the serum selenium content of healthy adults living in the Antwerp region (Belgium) with recent literature data. J Trace Elem Med Biol 18:99-112-112. https://doi. org/10.1016/j.jtemb.2004.04.004

4. Burri J, Haldimann M, Dudler V (2008) Selenium status of the Swiss population: assessment and change over a decade. J Trace Elem Med Biol 22:112-119. https://doi.org/10.1016/j.jtemb .2007 .11 .002

5. Letsiou S, Nomikos T, Panagiotakos D, Pergantis SA, Fragopoulou E, Antonopoulou S, Pitsavos C, Stefanadis C (2009) Serum total selenium status in Greek adults and its relation to age. The ATTICA study cohort. Biol Trace Elem Res 128:8-17. https://doi. org/10.1007/s12011-008-8252-2

6. Spina A, Guallar E, Rayman MP, Tigbe W, Kandala NB, Stranges $\mathrm{S}$

7. Galan-Chilet I, Tellez-Plaza M, Guallar E, De Marco G, LopezIzquierdo R, Gonzalez-Manzano I, Carmen Tormos M, MartinNunez GM, Rojo-Martinez G, Saez GT, Martin-Escudero JC, Redon J, Javier Chaves F (2014) Plasma selenium levels and oxidative stress biomarkers: a gene-environment interaction population-based study. Free Radic Biol Med 74C:229-236. https://doi. org/10.1016/j.freeradbiomed.2014.07.005

8. Rayman MP (2012) Selenium and human health. Lancet 379:1256-1268. https://doi.org/10.1016/S0140-6736(11)61452-9

9. U.S. Department of Agriculture ARS (2008) Nutrient intakes from food: mean amounts consumed per individual, one day, 2005-2006. https://www.ars.usda.gov/ba/bhnrc/fsrg. Accessed Mar 2010

10. Kafai MR, Ganji V (2003) Sex, age, geographical location, smoking, and alcohol consumption influence serum selenium concentrations in the USA: third National Health and Nutrition Examination Survey, 1988-1994. J Trace Elem Med Biol 17:13-18. https ://doi.org/10.1016/S0946-672X(03)80040-8

11. Bleys J, Navas-Acien A, Laclaustra M, Pastor-Barriuso R, Menke A, Ordovas J, Stranges S, Guallar E (2009) Serum selenium and peripheral arterial disease: results from the national health and nutrition examination survey, 2003-2004. Am J Epidemiol 169:996-1003

12. Bullon P, Roman-Malo L, Marin-Aguilar F, Alvarez-Suarez JM, Giampieri F, Battino M, Cordero MD (2015) Lipophilic antioxidants prevent lipopolysaccharide-induced mitochondrial dysfunction through mitochondrial biogenesis improvement. Pharmacol Res 91:1-8. https://doi.org/10.1016/j.phrs.2014.10.007

13. Xia L, Nordman T, Olsson JM, Damdimopoulos A, BjorkhemBergman L, Nalvarte I, Eriksson LC, Arner ES, Spyrou G, Bjornstedt M (2003) The mammalian cytosolic selenoenzyme thioredoxin reductase reduces ubiquinone. A novel mechanism for defense against oxidative stress. J Biol Chem 278:2141-2146

14. Kalen A, Appelkvist EL, Dallner G (1989) Age-related changes in the lipid compositions of rat and human tissues. Lipids 24:579-584

15. Alehagen U, Johansson P, Bjornstedt M, Rosen A, Dahlstrom U (2013) Cardiovascular mortality and N-terminal-proBNP reduced after combined selenium and coenzyme Q10 supplementation: a 5-year prospective randomized double-blind placebo-controlled trial among elderly Swedish citizens. Int J Cardiol 167:18601866. https://doi.org/10.1016/j.ijcard.2012.04.156

16. Huang J, Roth R, Heuser JE, Sadler JE (2009) Integrin alpha(v) beta(3) on human endothelial cells binds von Willebrand factor strings under fluid shear stress. Blood 113:1589-1597. https://doi. org/10.1182/blood-2008-05-158584

17. Padilla A, Moake JL, Bernardo A, Ball C, Wang Y, Arya M, Nolasco L, Turner N, Berndt MC, Anvari B, Lopez JA, Dong JF (2004) P-selectin anchors newly released ultralarge von Willebrand factor multimers to the endothelial cell surface. Blood 103:2150-2156. https://doi.org/10.1182/blood-2003-08-2956

18. Starke RD, Ferraro F, Paschalaki KE, Dryden NH, McKinnon TA, Sutton RE, Payne EM, Haskard DO, Hughes AD, Cutler DF, Laffan MA, Randi AM (2011) Endothelial von Willebrand factor regulates angiogenesis. Blood 117:1071-1080. https://doi. org/10.1182/blood-2010-01-264507

19. Kawecki C, Lenting PJ, Denis CV (2017) von Willebrand factor and inflammation. J Thromb Haemost 15:1285-1294. https://doi. org/10.1111/jth.13696

20. Rutten B, Maseri A, Cianflone D, Laricchia A, Cristell NA, Durante A, Spartera M, Ancona F, Limite L, Hu D, Li H, Uren NG, de Groot PG, Mannucci PM, Roest M (2015) Plasma levels of active Von Willebrand factor are increased in patients with first ST-segment elevation myocardial infarction: a multicenter and multiethnic study. Eur Heart J Acute Cardiovasc Care 4:64-74. https://doi.org/10.1177/2048872614534388

21. Wennberg P, Wensley F, Di Angelantonio E, Johansson L, Boman K, Rumley A, Lowe G, Hallmans G, Danesh J, Jansson JH (2012) Haemostatic and inflammatory markers are independently associated with myocardial infarction in men and women. Thromb Res 129:68-73. https://doi.org/10.1016/j.thromres.2011.05.015

22. Willeit P, Thompson A, Aspelund T, Rumley A, Eiriksdottir G, Lowe G, Gudnason V, Di Angelantonio E (2013) Hemostatic factors and risk of coronary heart disease in general populations: new prospective study and updated meta-analyses. PLoS ONE 8:e55175. https://doi.org/10.1371/journal.pone.0055175

23. Czekay RP, Wilkins-Port CE, Higgins SP, Freytag J, Overstreet JM, Klein RM, Higgins CE, Samarakoon R, Higgins PJ (2011) PAI-1: an integrator of cell signaling and migration. Int J Cell Biol 2011:562481. https://doi.org/10.1155/2011/562481

24. Declerck PJ, Gils A (2013) Three decades of research on plasminogen activator inhibitor-1: a multifaceted serpin. Semin Thromb Hemost 39:356-364. https://doi.org/10.1055/s-0033-1334487

25. Brogren H, Karlsson L, Andersson M, Wang L, Erlinge D, Jern S (2004) Platelets synthesize large amounts of active plasminogen activator inhibitor 1. Blood 104:3943-3948. https://doi. org/10.1182/blood-2004-04-1439

26. Lindahl TL, Ohlsson PI, Wiman B (1990) The mechanism of the reaction between human plasminogen-activator inhibitor 1 and tissue plasminogen activator. Biochem J 265:109-113. https://doi. org/10.1042/bj2650109

27. Yarmolinsky J, Bordin Barbieri N, Weinmann T, Ziegelmann PK, Duncan BB, Ines Schmidt M (2016) Plasminogen activator inhibitor-1 and type 2 diabetes: a systematic review and meta-analysis of observational studies. Sci Rep 6:17714. https://doi.org/10.1038/ srep 17714

28. Marcelino Rodriguez I, Oliva Garcia J, Aleman Sanchez JJ, Almeida Gonzalez D, Dominguez Coello S, Brito Diaz B, Gannar F, Rodriguez Perez MDC, Elosua R, Cabrera de Leon A (2016) Lipid and inflammatory biomarker profiles in early insulin resistance. Acta Diabetol 53:905-913. https://doi.org/10.1007/s0059 2-016-0885-6

29. Shimizu T, Uematsu M, Yoshizaki T, Obata JE, Nakamura T, Fujioka D, Watanabe K, Watanabe Y, Kugiyama K (2016) Myocardial production of plasminogen activator inhibitor-1 is 
associated with coronary endothelial and ventricular dysfunction after acute myocardial infarction. J Atheroscler Thromb 23:557_ 566. https://doi.org/10.5551/jat.32300

30. Praetner M, Zuchtriegel G, Holzer M, Uhl B, Schaubacher J, Mittmann L, Fabritius M, Furst R, Zahler S, Funken D, Lerchenberger M, Khandoga A, Kanse S, Lauber K, Krombach F, Reichel CA (2018) Plasminogen activator inhibitor-1 promotes neutrophil infiltration and tissue injury on ischemia-reperfusion. Arterioscler Thromb Vasc Biol 38:829-842. https://doi.org/10.1161/ATVBA HA.117.309760

31. Lalic K, Nedeljkovic M, Jotic A, Babic R, Rajkovic N, Popovic L, Lukic L, Milicic T, Singh Lukac S, Stosic L, Macesic M, Rasulic I, Gajovic JS, Lalic NM (2018) Endothelial dysfunction of coronary arteries in subjects without diabetes: an association with both insulin resistance and impaired insulin secretion response. Diabetes Res Clin Pract 139:179-187. https://doi.org/10.1016/j. diabres.2018.03.005

32. Jensen-Urstad K, Bouvier F, Hojer J, Ruiz H, Hulting J, Samad B, Thorstrand C, Jensen-Urstad M (1998) Comparison of different echocardiographic methods with radionuclide imaging for measuring left ventricular ejection fraction during acute myocardial infarction treated by thrombolytic therapy. Am J Cardiol 81:538-544

33. van Royen N, Jaffe CC, Krumholz HM, Johnson KM, Lynch PJ, Natale D, Atkinson P, Deman P, Wackers FJ (1996) Comparison and reproducibility of visual echocardiographic and quantitative radionuclide left ventricular ejection fractions. Am J Cardiol $77: 843-850$

34. Alexander J, Alehagen U, Larsson A, Aaseth J (2019) Selenium in clinical medicine and medical biochemistry. Klin Biokem I Nord 31:12-19

35. Alehagen U, Johansson P, Bjornstedt M, Rosen A, Post C, Aaseth J (2016) Relatively high mortality risk in elderly Swedish subjects with low selenium status. Eur J Clin Nutr 70:91-96. https://doi. org/10.1038/ejen.2015.92

36. European Food Safety Authority EFSA (2006) Opinion of the Scientific Committee on food on the tolerable upper intake level of selenium. In: Flynn A (ed) Tolerable upper intake levels for vitamins and minerals, pp 65-76. European Food Safety Authority. ISBN: 92-9199-014-0

37. Rayman MP, Winther KH, Pastor-Barriuso R, Cold F, Thvilum M, Stranges S, Guallar E, Cold S (2018) Effect of long-term selenium supplementation on mortality: results from a multiple-dose, randomised controlled trial. Free Radic Biol Med 127:46-54. https ://doi.org/10.1016/j.freeradbiomed.2018.02.015

38. Alehagen U, Lindahl TL, Aaseth J, Svensson E, Johansson P (2015) Levels of sP-selectin and hs-CRP decrease with dietary intervention with selenium and coenzyme Q10 combined: a secondary analysis of a randomized clinical trial. PLoS ONE 10:e0137680. https://doi.org/10.1371/journal.pone.0137680

39. Alehagen U, Alexander J, Aaseth J, Larsson A (2019) Decrease in inflammatory biomarker concentration by intervention with selenium and coenzyme Q10: a subanalysis of osteopontin, osteoprotergerin, TNFr1, TNFr2 and TWEAK. J Inflamm (Lond) 16:5. https://doi.org/10.1186/s12950-019-0210-6

40. Cho JG, Lee A, Chang W, Lee MS, Kim J (2018) Endothelial to mesenchymal transition represents a key link in the interaction between inflammation and endothelial dysfunction. Front Immunol 9:294. https://doi.org/10.3389/fimmu.2018.00294

41. Albanez S, Ogiwara K, Michels A, Hopman W, Grabell J, James P, Lillicrap D (2016) Aging and ABO blood type influence von Willebrand factor and factor VIII levels through interrelated mechanisms. J Thromb Haemost 14:953-963. https://doi. org/10.1111/jth.13294

42. Gragnano F, Sperlongano S, Golia E, Natale F, Bianchi R, Crisci M, Fimiani F, Pariggiano I, Diana V, Carbone A, Cesaro A, Concilio C, Limongelli G, Russo M, Calabro P (2017) The role of von Willebrand factor in vascular inflammation: from pathogenesis to targeted therapy. Mediat Inflamm 2017:5620314. https://doi. org/10.1155/2017/5620314

43. Horvath B, Hegedus D, Szapary L, Marton Z, Alexy T, Koltai K, Czopf L, Wittmann I, Juricskay I, Toth K, Kesmarky G (2004) Measurement of von Willebrand factor as the marker of endothelial dysfunction in vascular diseases. Exp Clin Cardiol 9:31-34

44. Akour A, Kasabri V, Bulatova N, Al Muhaissen S, Naffa R, Fahmawi H, Momani M, Zayed A, Bustanji Y (2018) Association of oxytocin with glucose intolerance and inflammation biomarkers in metabolic syndrome patients with and without prediabetes. Rev Diabet Stud 14:364-371. https://doi.org/10.1900/ RDS.2017.14.364

45. Somers EC, Marder W, Kaplan MJ, Brook RD, McCune WJ (2005) Plasminogen activator inhibitor-1 is associated with impaired endothelial function in women with systemic lupus erythematosus. Ann N Y Acad Sci 1051:271-280. https://doi. org/10.1196/annals.1361.068

46. Alehagen U, Aaseth J, Johansson P (2015) Less increase of copeptin and MR-proADM due to intervention with selenium and coenzyme Q10 combined: results from a 4-year prospective randomized double-blind placebo-controlled trial among elderly Swedish citizens. BioFactors 41:443-452. https://doi.org/10.1002/ biof. 1245

47. Alehagen U, Johansson P, Aaseth J, Alexander J, Wagsater D (2017) Significant changes in circulating microRNA by dietary supplementation of selenium and coenzyme Q10 in healthy elderly males. A subgroup analysis of a prospective randomized double-blind placebo-controlled trial among elderly Swedish citizens. PLoS ONE 12:e0174880. https://doi.org/10.1371/journ al.pone. 0174880

48. Brigelius-Flohe R, Banning A, Schnurr K (2003) Seleniumdependent enzymes in endothelial cell function. Antioxid Redox Signal 5:205-215. https://doi.org/10.1089/152308603764816569

49. Lopes Junior E, Leite HP, Konstantyner T (2019) Selenium and selenoproteins: from endothelial cytoprotection to clinical outcomes. Res Transl. https://doi.org/10.1016/j.trs1.2019.01.004

50. Stupin A, Cosic A, Novak S, Vesel M, Jukic I, Popovic B, Karalic K, Loncaric Z, Drenjancevic I (2017) Reduced dietary selenium impairs vascular function by increasing oxidative stress in Sprague-Dawley rat aortas. Int J Environ Res Public Health. https ://doi.org/10.3390/ijerph14060591

51. Mertens K, Lowes DA, Webster NR, Talib J, Hall L, Davies MJ, Beattie JH, Galley HF (2015) Low zinc and selenium concentrations in sepsis are associated with oxidative damage and inflammation. Br J Anaesth 114:990-999. https://doi.org/10.1093/bja/ aev073 


\section{Affiliations}

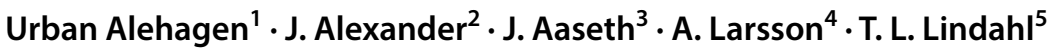

J. Alexander

Jan.Alexander@fhi.no

J. Aaseth

jaol-aas@online.no

A. Larsson

anders.larsson@medsci.uu.se

T. L. Lindahl

tomas.lindahl@liu.se

1 Division of Cardiovascular Medicine, Department of Medical and Health Sciences, Linköping University, 58185 Linköping, Sweden

2 Norwegian Institute of Public Health, 0403 Oslo, Norway
3 Research Department, Innlandet Hospital Trust, 2381 Brumunddal, Norway

4 Department of Medical Sciences, Uppsala University, 75185 Uppsala, Sweden

5 Division of Clinical Chemistry, Department of Experimental and Clinical Medicine, Linköping University,

58185 Linköping, Sweden 